\title{
Microbiological evaluation of the steam sterilization of assembled laparoscopic instruments ${ }^{1}$
}

\author{
Tamara Carolina de Camargo ${ }^{2}$ \\ Kazuko Uchikawa Graziano ${ }^{3}$ \\ Alda Graciele Claudio dos Santos Almeida ${ }^{4}$ \\ Karina Suzuki ${ }^{5}$ \\ Cely Barreto da Silva ${ }^{6}$ \\ Flávia Morais Gomes Pinto ${ }^{7}$
}

Objective: assess the safety of steam sterilization of assembled laparoscopic instruments with challenge contamination. Method: a laboratory experimental study, using as test samples trocars and laparoscopic graspers. Geobacillus stearothermophillus ATCC-7953 was used, with a microbial population of $106 \mathrm{UFC} /$ Filter paper substrate, removed from the biological indicator. Three of them were introduced into each instrument at the time of assembly, and sterilized at pressurized saturated steam, $1340 \mathrm{C}$ for 5 minutes. After sterilization, the instrument was disassembled and each filter paper substrate was inoculated in soybean casein culture and incubated at 56oC for 21 days. In case of absence of growth, they were subjected to heat shock of $800 \mathrm{C}$, for 20 minutes and re-incubated for 72 hours. Sample size: 185 graspers and 185 trocars, with $95 \%$ power. We paired the experiments with comparative negative control groups ( 5 graspers and 5 trocars with challenge contamination, sterilized disassembled) and positive control (30 filter paper supports, unsterilized), subject to the same incubation procedures. Results: there was no microbial growth in experimental and negative control. The results of the positive control were satisfactory. Conclusion: this study provided strong scientific evidence to support the safety of steam sterilizing of the assembled laparoscopic instrument.

Descriptors: Sterilization; Laparoscopy; Surgical Instruments; Operating Room Nursing; EvidenceBased Nursing; Nursing.

\footnotetext{
${ }^{1}$ Paper extracted from Doctoral Dissertation "Evaluation of steam sterilization of laparoscopic instruments assembled: laboratory approach", presented to Escola de Enfermagem, Universidade de São Paulo, São Paulo, SP, Brazil. This research was supported by Fundação de Amparo à Pesquisa do Estado de São Paulo (FAPESP), process \#2011/05759-0.

2 PhD, Assistant Professor, Faculdade de Ciências Médicas e da Saúde, Pontifícia Universidade Católica de São Paulo, Sorocaba, SP, Brazil.

${ }^{3}$ PhD, Full Professor, Escola de Enfermagem, Universidade de São Paulo, São Paulo, SP, Brazil.

${ }^{4} \mathrm{MSc}$, Doctoral student, Escola de Enfermagem, Universidade de São Paulo, São Paulo, SP, Brazil.

${ }^{5}$ PhD, Adjunct Professor, Faculdade de Enfermagem, Universidade Federal de Goiás, Goiânia, GO, Brazil.

${ }^{6}$ MSc, Pharmacy-Biochemistry, Santa Casa de Misericódia, São Paulo, SP, Brazil.

7 PhD, Professor Instructor, Faculdade de Ciências Médicas, Santa Casa de Misericórdia, São Paulo, SP, Brazil.
}

\section{How to cite this article}

Camargo TC, Graziano KU, Ameida AGCS, Suzuki K, Silva CB, Pinto FMG. Microbiological evaluation of the steam sterilization of assembled laparoscopic instruments. Rev. Latino-Am. Enfermagem. 2016;24:e2830.

[Access 8345.1431.2830
]; Available in: DOI: http://dx.doi.org/10.1590/1518- 


\section{Introduction}

The videolaparoscopic surgery is a technological innovation that has emerged as an alternative to surgical, diagnostic and therapeutic procedures, which were usually performed through laparotomy. This technique has indisputable advantages for the patients, and new challenges for the nurses responsible for the Sterile Supply Center (SSC), including the establishment of guidelines for the safe processing of instruments and accessories with complex conformation, understood as those with less than $5 \mathrm{~mm}$ of lumen or blind-end, inaccessible internal spaces for direct friction, holes or valves $^{(1)}$.

On the issue of sterilization, the pressurized saturated steam is the preferred method for heat resistant laparoscopic instrumental because it brings advantages such as low $D^{*}$ value, high diffusivity and penetration of the sterilizing agent, speed, atoxicity and lower $\operatorname{cost}^{(2)}$. In this process pressurized saturated steam in contact with the cold surface of the material disposed within the autoclave, undergoes condensation, releasing the latent heat of vaporization watering and simultaneously heating the material. This heat causes thermal coagulation of proteins and death of microorganisms, i.e. pressurized saturated steam sterilization is based on heat exchange between the medium and the object to be sterilized(3).

The classical recommendations state that the heat resistant surgical instruments are to be open, disassembled and with the surfaces free for steam sterilization ${ }^{(2,4-5)}$, including the laparoscopic ones. There are other guidelines that do not emphasize this kind of care ${ }^{(1,6)}$. There is no doubt that autoclaving of disassembled materials through thermal conduction provides the best condition.

Among health professionals, there is a deep-rooted concept that to achieve the success of the sterilization by the saturated pressure steam autoclave, direct contact of steam with all surfaces of materials is necessary, without considering the physical principles of latent heat. There is a need to question rooted concepts based on traditions, and strong scientific evidence should be sought in order to support decision-making in healthcare practice.

As laparoscopic accessories are complex instruments with several pieces of small size, if sterilized when completely dismantled, they can present problems for the surgical teams at the time of assembly in the operative field. It is noteworthy that some surgical scrub aides are unaware of the correct assembly, compromising their functionality, creating stress and disrupting the start of the surgical procedure.

The autoclaving of preassembled laparoscopic instruments is a reality identified by a survey, with a sample of 263 nursing professionals, in which $37 \%$ of respondents reported that in their institutions they sterilized the assembled laparoscopic instruments ${ }^{(7)}$. This practice aims at the optimization of time and security in the assembly process, but, on the other hand, there are surgical teams who question the SSC nursing team, asking if the sterilization through pressurized saturated steam of the assembled laparoscopic instruments is safe because it goes against the classical recommendations.

The scientific literature does not provide a conclusive answer about the safety of saturated steam pressure sterilization, of the assembled laparoscopic instrument (8-10), and it recommends conducting a new laboratory experimental test study ${ }^{(11)}$. To have an updated view we consulted the following portals and electronic databases on May 2016: PUBMED, BVS, EMBASE, SCOPUS e WEB OF SCIENCE, using the Boolean AND operator and controlled descriptors Medical Subject Headings (MeSH) steam, sterilization, laparoscopy e instruments. Three already known old articles were found(8-10), published in the years 1991, 1995 and 2011, with no recent publications on the subject studied.

Given the abovementioned result, this research aimed to evaluate the safety of steam sterilization, of the assembled laparoscopic instrument with challenge infection, in order to bring to the table robust scientific evidence to support the decisions of the nurses that manage the SSC, focusing on the safety of the surgical patients.

\section{Method}

This study is characterized as laboratory-based experimental. As test specimen we selected two types of reusable laparoscopic instruments that are more complex for reuse: Trocar with screw windowed valve, made of five parts, being one of them with a lumen of $5 \mathrm{~mm}$ diameter and $5 \mathrm{~mm}$ Dissection Forceps made of four parts with teethed end, lumen of $30 \mathrm{~cm}$ long and internal diameter of $3 \mathrm{~mm}$. The laparoscopic instruments used in the research were specific for this purpose and were not previously used in humans. 
The selected challenge microorganism was the Geobacillus stearothermophillus ATCC-7953 in sporulated form, a biologic indicator available in the market to monitor steam pressurized sterilization cycles (Attest ${ }^{\mathrm{TM}}{ }^{\circledR}$ biologic indicator, reference 1.262, readings after $48 \mathrm{hs}$, steam). The self-contained biologic indicator is built in a paper substrate $(2.5 \times 0.5 \mathrm{~cm})$ with a minimum of 100,000 calibrated dry spores of Geobacillus stearothermophillus ATCC-7953. We chose this microorganism because it is the standard for biologic monitoring of the efficacy control in autoclave cycles, due to its resistance to humid heat and low pathogenic conditions under normal conditions ${ }^{(12)}$.

Three groups were defined: an experiment group, a negative control and a positive control. In the experimental group we analyzed the results of microbial culture from 370 assembled laparoscopic instruments, coming from 185 graspers and 185 trocars, for a total of 1080 sampling units. This sampling size showed to have a $95 \%$ sample power, in which the chance of the assembled instrument of presenting viable spores after sterilization is at least $8 \%$. As negative control group, 10 disassembled laparoscopic instruments were analyzed, composed of 5 graspers and 5 trocars, for a total of 30 sampling culture units. The positive control was a set of 30 non-sterilized paper filter substrate, inoculated seeding directly in $\mathrm{TSB}, 56^{\circ} \mathrm{C}$ for 48 hours.

The biologic indicator small tubes were disassembled using an aseptic technique, and the substrate papers with the Geobacillus stearothermophillus ATCC-7953 were separated. Three units of paper substrate were placed inside of each laparoscopic instrument in the process of assemblage (Figure 1 ).

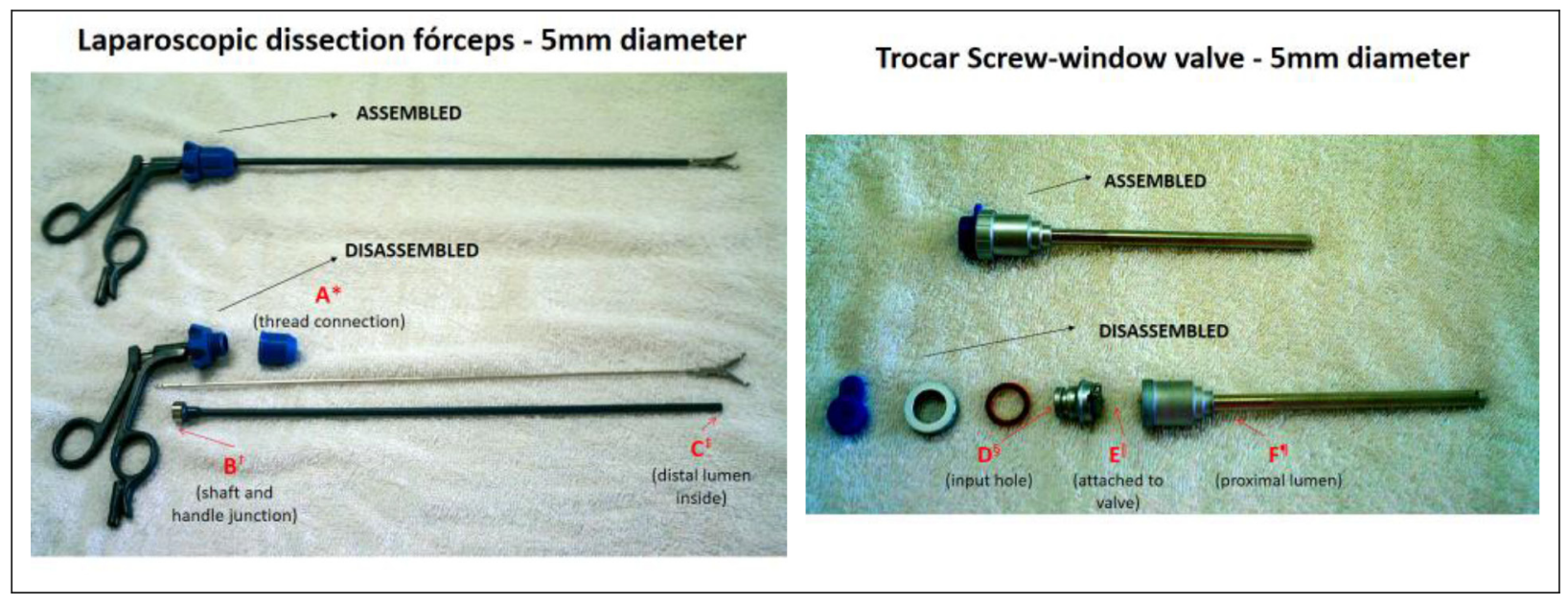

*Position A: thread connection of the laparoscopic dissection forceps.

†Position B: Shaft and handle junction of the laparoscopic dissection forceps.

¥Position C: Distal lumen inside of the laparoscopic dissection forceps.

$\S$ Position D: Trocar input hole with screw-window valve.

Position E: Attached to trocar with screw-window valve.

qPosition F: proximal lumen of trocar with screw-window valve.

Figure 1 - Placement of biologic indicators in the assemblage of laparoscopic instruments in positions A, B and C. Sao Paulo, SP, Brazil, 2014

The instruments were packed individually in surgical grade paper and autoclaved in pressured saturated steam, with pre-vacuum autoclave $\mathrm{Cisa}^{\circledR}$ model $6412 \mathrm{HF}, 558$ liters, micro processed, thermal qualification for sterilization of surgical material at 134 Co for 5 minutes.

After sterilization, the instruments were disassembled inside the biologically protected cabinet using aseptic techniques, and each biologic indicator paper substrates was seeded in Tryptic Soy Broth (TSB) culture medium, incubated at $56^{\circ} \mathrm{C}$ for 21 days. If no microbiologic growth was observed after this time, tubes were exposed to a thermal shock during 20 minutes at $80^{\circ} \mathrm{C}$, re-incubating for 72 hs. at $56^{\circ} \mathrm{C}$ for a final reading ${ }^{(13)}$. This final process aimed to stimulate germination of spores that may have survived to autoclave. 
The TSB culture medium that were used in the experiment were prepared form dehydrated media, as per manufacturer recommendation ${ }^{(14)}$. As and sterilization control of culture medium, $5 \%$ of the tubes were incubated at $36^{\circ} \mathrm{C}$ during 7 days ${ }^{(15)}$. No microbiologic growth occurred in the samples.

\section{Results}

The results of the experiments are presented in Table 1. Positive controls showed satisfactory growth confirming the challenge in the experiments, as well as the viability of the culture media and the adequacy of the incubation conditions for spore germination.

Table 1 - Results of the culture of paper substrate impregnated with spores coming form the Biologic Indicators (BI), inserted in the laparoscopic instruments assembled prior to sterilization (Experimental Group), of the Negative Control and of the Positive Control. Sao Paulo, SP, Brazil, 2013

\begin{tabular}{|c|c|c|c|c|}
\hline Study Groups & Instrument Types & $\mathbf{N}$ & $\begin{array}{c}\mathrm{Bl}^{*} \\
\text { Placement }\end{array}$ & $\begin{array}{l}\text { +/total } \\
\text { Cultures }\end{array}$ \\
\hline \multirow[t]{6}{*}{ Experimental Group } & Laparoscopic Dissection Forceps & 185 & A & 0/185 \\
\hline & & & B & $0 / 185$ \\
\hline & & & C & $0 / 185$ \\
\hline & Trocar & 185 & $\mathrm{D}$ & $0 / 185$ \\
\hline & & & $\mathrm{E}$ & $0 / 185$ \\
\hline & & & $\mathrm{F}$ & $0 / 185$ \\
\hline \multirow[t]{6}{*}{ Negative Control } & Laparoscopic Dissection Forceps & 5 & A & $0 / 5$ \\
\hline & & & B & $0 / 5$ \\
\hline & & & C & $0 / 5$ \\
\hline & Trocar & 5 & $\mathrm{D}$ & $0 / 5$ \\
\hline & & & $\mathrm{E}$ & $0 / 5$ \\
\hline & & & $\mathrm{F}$ & $0 / 5$ \\
\hline Positive Control & & 30 & & $30 / 30$ \\
\hline
\end{tabular}

*BI (Biologic Indicator).

\section{Discussion}

The present laboratory controlled research succeeded in sterilizing assembled laparoscopic instruments in pressurized saturated steam, thus proving the microbiologic safety of this procedure. An thermally qualified autoclave was used following the recommended parameters for pressurized saturated stem with pre-vacuum, at $134^{\circ} \mathrm{C}$ for 5 minutes ${ }^{(2,4)}$, associated to challenge contamination with spores Geobacillus stearothermophillus ATCC-7953 in three times $10^{6}$ UFC concentration, sterilization tests with direct inoculation method and a sample size that demonstrated robust results.

Autoclave sterilization of assembled laparoscopic instruments is a reality in Brazilian healthcare facilities ${ }^{(7)}$, against the classic recommendations that mandate the disassembling and opening of surgical instruments, exposing free surfaces to sterilization ${ }^{(2,4-5)}$. Results for the present research brings up strong scientific evidence of the safety of using pressurized saturated steam for sterilizing assembled laparoscopic instruments, supporting the regular practice in Brazilian institutions. The provision of pre-assembled laparoscopic instruments 
by the SSC'S is an important facilitator and accelerator of the beginning of surgical procedures.

Sterilization of assembled laparoscopic instruments was studied previously ${ }^{(8-10)}$, concluding both positive and negative related to the practice of autoclaving assembled instruments, in spite of methodological issues arising form several of these papers.

The first research(8) proposed the hypothesis that the assembled laparoscopic instrument would have the same sterilization safety compared to the disassemble instrument, using vegetative bacteria suspension (Serratia marcescens) and sporulated bacteria (Bacillus subtilis e Bacillus stearothermophilus) as challenge contamination of two laparoscopic graspers and two trocars $(5 \mathrm{~mm}$ and $10 \mathrm{~mm}$ respectively). The inoculation technique and retrieval was done through swabs, retrieving the challenge microorganism both in assembled and disassembled laparoscopic sterilized instruments. In spite of the fact that the swab technique allows for a quantitative evaluation, it has limitations in standardizing the rolling resistance, the angle and the pressure degree during the procedure, it is not able to control reproducibility, and results have a large degree of variability(16)

In this same research ${ }^{(8)}$ the authors question the fact of not having success in sterilization with disassembled instruments; something generally considered a best autoclaving practice. In the present research, we have succeeded in sterilization with pressurized saturated steam both of assembled and disassembled laparoscopic instruments. Worth of note is the methodological rigor, the $95 \%$ sample power, the challenge contamination with spores of Geobacillus stearothermophilus in far higher concentration than the concentration found in worst case scenarios in clinical practice, associated with direct inoculation sterilization tests, ensuring full retrieval of viable microorganisms, respecting the incubation timing to allow the possible surviving spores may germinate after the thermal shock physical stimulus.

A different research ${ }^{(9)}$ used one of the parts of the laparoscopic instrument, a $12 \mathrm{~mm}$ trocar with its lumen filled with organic material (hamburger meat) and microbial challenge contamination to assess the efficacy of sterilization using $132^{\circ} \mathrm{C}$ in conventional and flash cycles with exposures of 10 and 3 minutes respectively. All vegetative microorganisms were eliminated with conventional and flash cycles of sterilization. Filling of the lumen with organic material showed resistance to direct steam contact, similar to the case when the laparoscopic instruments are sterilized while assembled.

In the same conditions, with organic material as lumen filling (9) researchers tested commercial biologic indicators Geobacillus stearothermophilus ATCC 7953 in the trocar lumen without hamburger meat and different time exposures, 3, 4,5 and 6 minutes. Only when time exposure was extended from 7 to 10 minutes the spores were fully destroyed. These results are in favor of the latent heat microbial destruction, in spite of the hard scenario of challenge contamination and massive organic material.

As the standard parameters for pressurized saturated steam with pre-vacuum autoclave are $134^{\circ} \mathrm{C}$ in 4 minutes ${ }^{(2,4)}$ the researchers' need (9) of extending the sterilization time to succeed in fully eliminating the test microorganisms may be linked to the high concentration of organic material used in filling the trocar lumen, and not necessarily to the fact of the assembled trocars. The present research used the same microbiological challenge and succeeded in destroying the spores Geobacillus stearothermophilus ATCC 7953 using pressurized saturated steam with pre-vacuum sterilization cycle at $134^{\circ} \mathrm{C}$ in 5 minutes.

Another research(10) that assessed the efficacy of sterilization of single-use laparoscopic instruments, used as comparison group 50 reusable equivalent instruments that were autoclaved assembled. The challenge contamination was Geobacillus stearothermophilus ATCC 7953 with $10 \%$ of lamb blood. Instruments passed though automated cleaning in ultrasonic washer with intermittent flow and hand cleaning before assembling and sterilization under pressurized saturated steam with pre-vacuum at $134134^{\circ} \mathrm{C}$ in 5 minutes. No microorganisms were retrieved in this group, reinforcing the chance of safety of sterilization under pressurized saturated steam of assembled instruments.

Researchers ${ }^{(10)}$ through instrument cleaning had certainly reduced contamination, thus being impossible to quantify the real challenge imposed in the experiment to asses the assembled instrument sterilization. In the case of our research, three units of substrate paper impregnated with Geobacillus stearothermophilus $10^{6}$ UFC were placed inside each laparoscopic instrument before sterilization, thus creating a three fold $10^{6}$ UFC challenge of the test microorganism in each sample unit. 


\section{Conclusion}

Sterilization under pressurized saturated steam of assembled laparoscopic instruments is microbiologically safe, breaking with the paradigm of classic recommendations of autoclaving only disassembled material. Results of this research, under the experiment conditions, are strong scientific evidence that supports a systematic review of this topic and gives inputs to the decision-making process related to the microbiological safety of pressurized saturated steam sterilization of assembled laparoscopic instruments. Additionally, it is desirable that it may give inputs to lawmakers to formalize the possibility of autoclaving pre-assembled laparoscopic instruments.

\section{References}

1. Ministério da Saúde (BR). Agência Nacional de Vigilância Sanitária. [Internet]. Resolução da Diretoria Colegiada n. 15, de 15 de março de 2012. Dispõe sobre requisitos de boas práticas para o processamento de produtos para saúde e dá outras providências. Diário Oficial da União, Poder Executivo, Brasília (DF); 2012 mar. 19. [Acesso 31 maio 2016]. Disponível em: http:// www.abih.net.br/wp-content/uploads/RDC-15-ANVISA_ Processamento-Artigos-15Mar2012.pdf

2. Rutala WA, Weber JD. Healthcare Infection Control Practices Advisory Committee (HICPAC). Guideline for disinfection and sterilization in healthcare facilities [Internet]. Atlanta: CDC; 2008. [Access May 31 2016]. 158 p. Available from: http://www.cdc.gov/hicpac/pdf/ guidelines/Disinfection_Nov_2008.pdf

3. Francis MJ, Pashley RM. Application of a bubble column for

evaporative cooling and a simple procedure for determining the latent heat of

vaporization of aqueous salt solutions. J Phys Chem B. [Internet] 2009 [Access May 31 2016];113(27):93115. Disponível em: http://pubs.acs.org/doi/pdf/10.1021/ jp901801k

4. American National Standard. Association for the Advancement of Medical Instrumentation. Comprehensive Guide to Steam Sterilization and Sterility Assurance in Health Care Facilities. Arlington (USA); 2006. ISBN 9781570204203
5. Committee on Infection Control in the Handling of Endoscopic Equipment. Guidelines for preparation of laparoscopic instrumentation. AORN J. 1980;32(1):6576. DOI: http://dx.doi.org/10.1016/S01966553(96)90066-8

6. Association of Perioperative Registred Nurse. Guidelene for Sterilization. In: Guideline for perioperative practice. Denver: AORN; 2016. p. 823-50.

7. Camargo TC, Feitosa AS, Graziano UK. Identificação e análise da prática de esterilização do instrumental laparoscópico montado. Rev SOBECC [Internet]. 2014 [Acesso 31 maio 2016];19(4):195-200. Disponível em: http://www.itarget.com.br/newclients/sobecc.org. br/2014/pdfs/revista-out-dez-2014.pdf.

8. Marshburn PB, Rutala WA, Wannamaker NS, Hulka JF. Gas and steam sterilization of assembled versus disassembled laparoscopic equipment. Microbiologic studies. J Reprod Med. 1991;36(7):483-7.

9. Voyles CR, Sanders DL, Simons JE, McVey EA, Wilson WB. Steam sterilization of laparoscopic instruments. Surg Laparosc Endosc. 1995; 5(2):139-41.

10. Lopes CLBC, Graziano KU, Pinto TJA. Evaluation of Single-use Reprocessed Laparoscopic Instrument Sterilization. Rev. Latino-Am. Enfermagem. [Internet]. 2011 [Access May 31 2016];19(2):370-7. Available from: http://www.scielo.br/scielo.php?script=sci_ arttext\&pid=S0104-11692011000200020\&lng=en\&nrm =iso\&tlng=en

11. Camargo TC, Rocha CDA, Graziano KU. Steam sterilization of previously-assembled laparoscopic instruments. Acta Paul Enferm. [Internet]. 2008 [Access May 31 2106];21(3):493-7. Available from: http://www.scielo.br/scielo.php?script=sci_arttext\&pid $=$ S0103-21002008000300018

12. Albert H, Davies DJG, Woodson LP, Soper CJ. Biological indicators for steam sterilization: characterization of a rapid biological indicator utilizing Bacillus stearothermophilus spore-associated alphaglucosidase enzyme. J Appl Microbiol. [Internet]. 1998 [Access May 31 2106];85(5):865-74. Available from: http://www.ncbi.nlm.nih.gov/pubmed/9830122

13. Sterility test. The United States Pharmacopeia [Internet]. Rockville: The United States Pharmacopeia. 31st ed. Rockville: United States Pharmacopeial Convention; 2008. 
[Acesso 1 jun 2016]. Disponível em: http://www. pharmacopeia.cn/v29240/usp29nf24s0_c71. html\#usp29nf24s0_c71

14. Zimbro MJ, Power DA, Miller SM, Wilson GE, Johnson JA. Manual of Microbiological Culture Media. 2nd.ed. Maryland (USA): BD; 2009 [Acesso 31 maio 2016]. p. 579-82. Disponível em: https://www.bd.com/ds/ technicalCenter/misc/difcobblmanual_2nded_lowres.pdf 15. Arghyros M, Douglass G, Löcher M, Mugg P, Myatt DC, Olma T, Scholtes A, Wilkinson I. Guidelines for assuring quality of medical microbiological culture media [Internet]. 2nd ed. Melbourne (Vic): Australian Society for Microbiology; 2012 [Access May 312016]. Available from: http://www.theasm.org.au/assets/ASM-Society/ Guidelines-for-the-Quality-Assurance-of-MedicalMicrobiological-culture-media-2nd-edition-July-2012. pdf

16. Moore G, Griffith. Problems associated with traditional hygiene swabbing: the need for in-house standardization. J Applied Microbiol. [Internet]. 2007 [Access May 31 2016];103:1090-103. Available from: http://onlinelibrary.wiley.com/doi/10.1111/j.13652672.2007.03330.x/pdf Creative Commons (CC BY).

This license lets others distribute, remix, tweak, and build upon your work, even commercially, as long as they credit you for the original creation. This is the most accommodating of licenses offered. Recommended for maximum dissemination and use of licensed materials. 